\title{
p53 can inhibit cell proliferation through caspase- mediated cleavage of ERK2/MAPK
}

\author{
A Marchetti ${ }^{1,4}$, B Cecchinelli ${ }^{1}$, M D'Angelo ${ }^{1}$, G D'Orazi $^{1,2}$, \\ M Crescenzi ${ }^{3}$, A Sacchi $^{1}$ and S Soddu ${ }^{*, 1}$ \\ ${ }^{1}$ Molecular Oncogenesis Laboratory, Department of Experimental Oncology, \\ Regina Elena Cancer Institute, 00158 Rome, Italy \\ 2 Department of Oncology and Neurosciences, University 'G D'Annunzio', 66013 \\ Chieti, Italy \\ ${ }^{3}$ Laboratory of Comparative Toxicology and Ecotoxicology, Istituto Superiore di \\ Sanità, 00160 Rome, Italy \\ 4 Present address: Department of Cellular Biotechnologies and Hematology, \\ University 'La Sapienza', Policlinico Umberto I, 00161 Rome, Italy \\ * Corresponding author: S Soddu, Molecular Oncogenesis Laboratory, \\ Department of Experimental Oncology, Regina Elena Cancer Institute, 00158 \\ Rome, Italy. Tel: + 3906 52662563; Fax: + 3906 4180526; \\ E-mail: soddu@ifo.it
}

Received 08.5.03; revised 01.6.03; accepted 11.10.03; published online 02.01.04 Edited by G Melino

\section{Abstract \\ Stimulation of the Ras/MAPK cascade can either activate p53 and promote replicative senescence and apoptosis, or degrade p53 and promote cell survival. Here we show that p53 can directly counteract the Ras/MAPK signaling by inactivating ERK2/MAPK. This inactivation is due to a caspase cleavage of the ERK2 protein and contributes to p53-mediated growth arrest. We found that in Ras-transformed cells, growth arrest induced by $\mathrm{p} 53$, but not p21 Waf1, is associated with a strong reduction in ERK2 activity, phosphorylation, and protein half-life, and with the appearance of caspase activity. Likewise, DNA damage-induced cell cycle arrest correlates with p53-dependent ERK2 downregulation and caspase activation. Furthermore, caspase inhibitors or expression of a caspase-resistant ERK2 mutant interfere with ERK2 cleavage and restore proliferation in the presence of p53 activation, indicating that caspase-mediated ERK2 degradation contri- butes to p53-induced growth arrest. These findings strongly point to ERK2 as a novel p53 target in growth suppression. \\ Cell Death and Differentiation (2004) 11, 596-607. \\ doi:10.1038/sj.cdd. 4401368 \\ Published online 2 January 2004}

Keywords: p53 target; signal transduction; growth arrest; protein degradation; caspases

Abbreviations: Ad, adenovirus; ADR, adriamycin; dnp53, dominant-negative p53; LMB, leptomycin B; MBP, myelin basic protein; m.o.i., multiplicity of infection; p.i., postinfection; PI, propidium iodide; TCE, total cell extract; WB, Western blotting

\section{Introduction}

The mitogen-activated protein kinase (MAPK) cascade consists of a series of serine/threonine kinases sequentially activated downstream of the small G-protein Ras. ${ }^{1}$ Activation of the extracellular signal-regulated kinases 1 and 2 (ERK1 and ERK2) is required for mitogenesis, and mediates neoplastic transformation signals from a wide variety of oncogenic stimuli. ${ }^{1}$ Accumulating evidence indicates that the extent and intensity of MAPK activation, as well as the cellular context, influence the biological outcomes. ${ }^{2}$ Indeed, besides the mitogenic response, MAPK can promote growth arrest, differentiation, replicative senescence, apoptosis, or resistance to radio- and chemotherapy. ${ }^{3-5}$ Some of these events were shown to involve the p53 oncosuppressor. ${ }^{4-6}$ In particular, constitutive Ras/MAPK signaling in primary human and murine fibroblasts activates p53 and induces premature senescence. This biological outcome cannot be obtained in p $53^{-1-}$ fibroblasts and is regarded as a safeguard mechanism against uncontrolled mitogenic stimuli and subsequent tumor transformation. ${ }^{7}$ Recently, induction of apoptosis by DNA damage or p53 overexpression was shown to correlate with increased levels of phosphorylated ERK2 and p53-mediated transcriptional activation of the ras promoter. ${ }^{8,9}$ Interestingly, the opposite effect (i.e., resistance to apoptosis) was also found to depend on the inhibition of p53 function by Ras/ MAPK pathway through the transcriptional activation of the Mdm2 gene. ${ }^{5}$

The ability of Ras to activate p53 has been extensively studied. It was found to associate with the ERK-mediated transcriptional induction of the cyclin D1 gene, with consequent hyperphosphorylation of the $\mathrm{pRb}$ protein and release of the E2F-1 transcription factor. ${ }^{10}$ The free E2F-1 can directly increase the expression levels of $\mathrm{p} 14^{\mathrm{ARF}}$ through direct transcriptional activation. ${ }^{11}$ ARF was shown to inhibit the p53-MDM2 association that maintains p53 in its inactive form. ${ }^{12}$ Recently, oncogenic Ras was also shown to activate p53 through its phosphorylation, acetylation, and relocalization in the PML nuclear bodies. ${ }^{13}$

While the biochemical pathways involved in $\mathrm{p} 53$ activation by the Ras/MAPK cascade are becoming clear, it is presently unknown whether this type of p53 activation necessarily drives the cells toward an irreversible biological outcome (e.g., senescence or apoptosis), or whether a negative regulation of this Ras-MAPK-p53 sequential activation pathway exists and contributes to transient and reversible p53-mediated cellular responses. Since p53 activation by different stress signals can induce a transient growth arrest, it can be hypothesized that p53 is activated by Ras/MAPK only when a point of no return is reached or required (e.g., nonrepairable damage or uncontrolled mitogenesis in primary cells). Alternatively, p53 might negatively regulate the Ras/MAPK signaling pathway and block signal transduction. Here we show that p53 can directly interfere with the Ras/MAPK cascade by inactivating ERK2/MAPK. Furthermore, we found that this inactivation is due to a caspase-mediated cleavage of the ERK2 protein that is required for p53-mediated cell cycle arrest, strongly indicating that ERK2 is a p53 target for growth suppression. 


\section{Results}

\section{ERK2 is downregulated upon DNA damage through a p53-mediated mechanism}

Following exposure to DNA damage, activation of the Ras/ MAPK signal transduction pathway has been observed. ${ }^{8,14}$ To evaluate whether p53 can counteract this Ras/MAPK activation in growth arresting conditions, ERK2 expression and phosphorylation levels were analyzed in cells expressing wildtype p53 (wtp53) or a dominant-negative p53 (dnp53) mutant after exposure to nonapoptotic doses of the DNA-damaging agent doxorubicin (adriamycin: ADR). wtp53-carrying C2C12 myoblasts (C2-LX) and their dnp53-expressing counterparts (C2-DD) were treated with ADR at the inhibitory concentration $50\left(\mathrm{IC}_{50}\right)$. As previously observed ${ }^{15}$ (Figure 1a), this dose promoted an accumulation of the control C2-LX cells in both G1 and G2 phases of the cell cycle within 12-18 h without induction of apoptosis ( $<3 \%$ of TUNEL-positive cells in untreated and treated populations). In contrast, the same treatment induced a massive accumulation of C2-DD cells in the G2/M phase (Figure 1a), which is due to cell cycle progression through mitosis and acquisition of a micronucleated phenotype. ${ }^{15}$ When a time-course analysis of p53 and ERK2 expression was performed, increased levels of phos- phorylated ERK2 in C2-LX cells were found early after treatment (Figure 1b), as previously observed. ${ }^{8}$ However, at later time points, the levels of ERK2 protein and phosphorylation drastically decreased in the C2-LX cells (compare time point 12 and $14 \mathrm{~h}$ to $9 \mathrm{~h}$ in Figure $1 \mathrm{~b}$ ). This kinetics was lost in C2-DD cells, indicating its dependence on a functional p53 protein. To confirm the p53 dependency of this phenomenon,

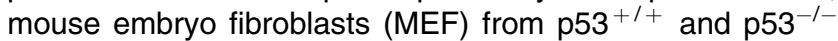
mice were treated with a growth-arresting dose of ADR and analyzed for cell cycle profile and ERK2 expression and phosphorylation. As shown in Figure $1 \mathrm{c}$ and $\mathrm{d}$, the results were comparable to those obtained with the $\mathrm{C} 2 \mathrm{C} 12$ cells. Thus, during cell response to ADR-induced growth arrest, persistent p53 accumulation is associated with a downregulation of ERK2.

\section{p53-induced growth arrest of v-Ha-ras- transformed cells is associated with ERK2 inactivation}

To confirm the ability of p53 to downregulate the MAPK cascade, cells with a constitutively activated Ras were employed. Immortal C2C12 myoblasts and NIH3T3 fibroblasts were transformed with the v-Ha-Ras oncogene by a
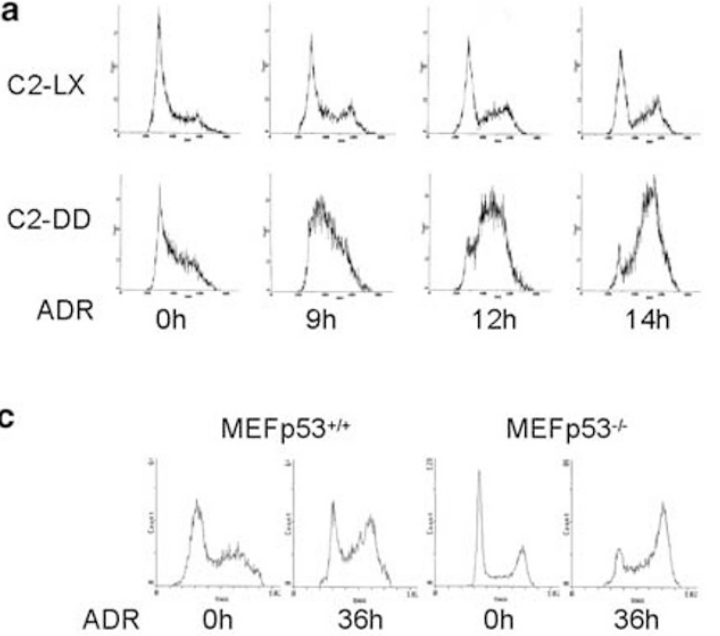

b

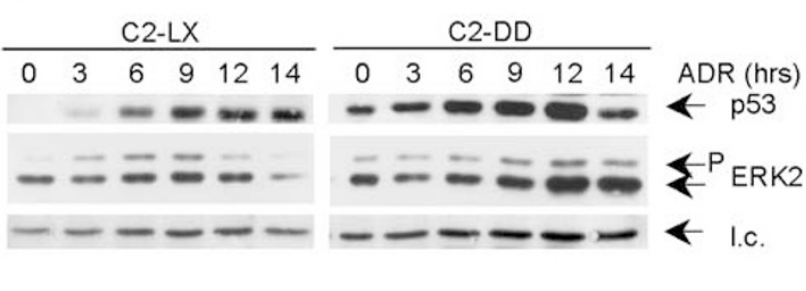

d

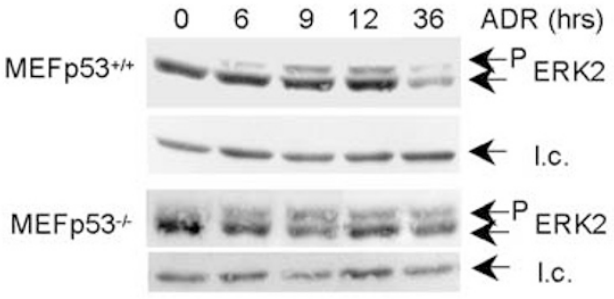

e

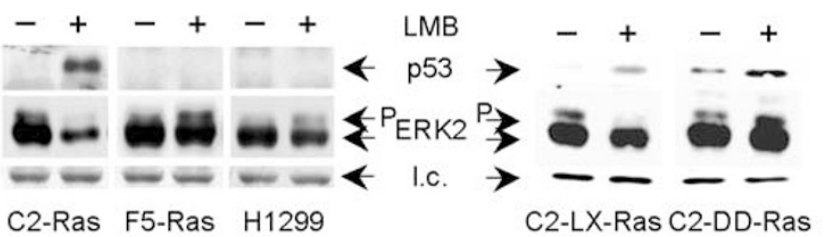

Figure 1 ERK2 modulation following activation of endogenous p53. (a) DNA content analysis of C2C12 cells expressing wtp53 (C2-LX) or dominant-negative p53 mutant (C2-DD) after treatment with ADR for the indicated times. Cells were stained with propidium iodide (PI) and analyzed by flow cytometry. (b) Western blot (WB) analyses of p53 and ERK2 proteins on total cell extracts (TCEs) from cells treated as in (a). Expression of dnp53 protein (i.e., the p53 oligomerization domain DD ${ }^{43}$ ) stabilized the endogenous p53 protein as expected. ERK2 expression and phosphorylation were detected by C-14 Ab that recognizes both the unphosphorylated and phosphorylated forms of ERK2. The phosphorylated form $(P)$ was separated from the unphosphorylated one by the difference in electrophoretic mobility. Loading control (I.c.: $\alpha$-tubulin) is indicated. The time course reported is one indicative experiment of three independent analyses performed. (c,d) Cell cycle profiles and ERK2 expression in MEFs explanted from $\mathrm{p} 53^{+1+}$ and $\mathrm{p} 53^{-1-}$ mice as described in $(\mathbf{a}, \mathbf{b})$. (e) The indicated cells were cultured in the presence or absence of LMB for $18 \mathrm{~h}$. TCEs were analyzed by WB for p53 and ERK2 as in (b) 
retroviral infection, obtaining the $\mathrm{C} 2-$ Ras and the $\mathrm{NIH}$-Ras cells, respectively. Both cell populations were used for the following experiments with consistent results, though, for space sparing, the data obtained with one or the other are shown. Accumulation of the endogenous wtp53 protein in Ras-transformed cells was stimulated by treatment with leptomycin B (LMB), a specific inhibitor of nuclear export. ${ }^{16}$ This treatment promotes p53 stabilization and activation, at least in part by preventing its MDM2-mediated proteolytic degradation. ${ }^{17}$ Consequently, cells arrest in the $\mathrm{G} 1$ phase of the cell cycle, in part through p53-dependent mechanisms. ${ }^{18}$ As expected, LMB treatment of C2-Ras cells increased p53 protein levels (Figure 1e) and nuclear accumulation, and promoted cell cycle arrest (data not shown). A strong decrease in ERK2 protein levels and phosphorylation was found in LMB-treated C2-Ras cells, while no ERK2 alteration was observed in the same C2-Ras cells expressing the dnp53 mutant (C2-DD-Ras), or in p53-null cells, such as fibroblasts from $\mathrm{p} 53^{-/-}$mice transformed with $\mathrm{v}-\mathrm{Ha}$-Ras (F5-Ras) and
H1299 lung adenocarcinoma cells (Figure 1e). These results show that activation of the endogenous p53 induces ERK2 downregulation in Ras-transformed cells; furthermore, they indicate that LMB-induced ERK2 downregulation requires the presence of $\mathrm{p} 53$ protein.

To further and directly evaluate the interference of p53 on the Ras/MAPK cascade avoiding p53-independent pathways activated by drugs, wtp53 protein was overexpressed in Rastransformed cells by infection with the Adp53 recombinant adenovirus. Adp53 infection strongly reduced the proliferation rate of the Ras-transformed cells (Figure $2 \mathrm{a}$ ), with a reduction of BrdU incorporation (Figure 2b) and a preferential accumulation in the G2/M phase of the cell cycle (Figure 2c) as reported in other systems, ${ }^{19}$ without induction of apoptosis (Figure 2c; $<5 \%$ of TUNEL-positive cells in both $\mathrm{dl} 70.3$ control virus- and Adp53-infected cells). TUNEL and/or viability controls, to ensure the absence of cell death, were performed in each of the following experiments. As observed following activation of the endogenous p53, the



d


C

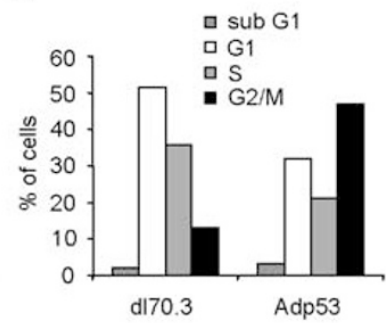

e

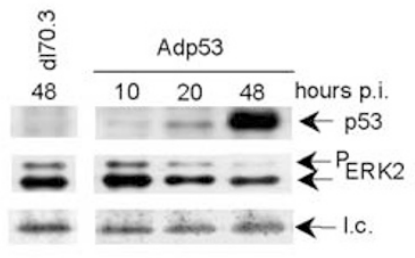

$\begin{array}{lllll}31.2 & 32.5 & 31.3 & 15 & \text { S phase (\%) }\end{array}$

g

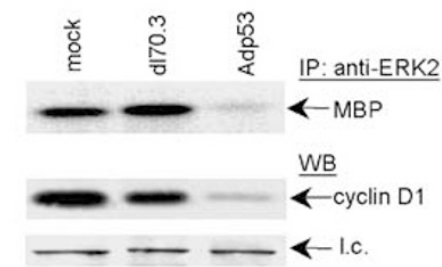

Figure 2 wtp53 overexpression inhibits cell proliferation and downregulates ERK2 in Ras-transformed cells. (a) Proliferation rate of C2-Ras and NIH-Ras cells following p53 overexpression. Cells in replica plates were infected with the indicated viruses at m.0.i. $3 \times 10^{3}$. The empty virus dl70.3 was used as control. Approximately $90 \%$ of the Adp53-infected cells express p53 (unpublished data). The number of viable cells was daily evaluated in duplicate. Means \pm standard deviations (S.D.) are reported. (b) Analyses of DNA synthesis in C2-Ras and NIH-Ras cells, infected as in (a). At $72 \mathrm{~h}$ postinfection (p.i.), cells were pulsed for $2 \mathrm{~h}$ with BrdU and analyzed by indirect immunofluorescence (IF). Means \pm S.D. of three independent experiments are presented. (c) DNA content analysis of C2-Ras cells $72 \mathrm{~h}$ p.i. Cells were stained with PI and analyzed by flow cytometry. The percentages of cells in the different phases of the cell cycle and those belonging to the sub-G1 peaks are indicated. (d) WB analyses of $p 53$ and ERK2 protein expression in C2-Ras cells after infection at $3 \times 10^{3}$ m.o.i. with the indicated viruses. (e) Time-course analysis of p53 and ERK2 expression following Adp53 infection. C2-Ras cells were infected with the indicated viruses and collected at the indicated times for WB or for cell cycle analyses. The percentages of cells in the S phase, determined by flow cytometry, are indicated at the bottom. (f) Dose-dependent downregulation of ERK2 by p53 in NIH-Ras cells. Cells were infected with an increasing amount of Adp53 $\left(5 \times 10^{2}, 1 \times 10^{3}\right.$, and $2 \times 10^{3}$ m.o.i. $)$ or with dll70.3 $\left(2 \times 10^{3}\right.$ m.o.i.) and lysed $72 \mathrm{~h} \mathrm{p.i.} \mathrm{for} \mathrm{WB,} \mathrm{as} \mathrm{above.} \mathrm{The}$ phosphorylated forms of ERK1 and ERK2 were also immunodetected with the anti-phospho-MAPKs Ab (bottom line). (g) In vitro and in vivo ERK2 kinase activity. TCEs from cells infected with the indicated adenoviruses were engaged in a kinase assay on the MBP substrate, following immunoprecipitation with anti-ERK2 C-14 Ab, or analyzed by WB with anti-cyclin D1 Ab 
Adp53-induced inhibition of cell proliferation correlated with a strong reduction in the amount of phosphorylated ERK2, as well as that of the total ERK2 protein (Figure 2d). This effect was an early event following exogenous p53 expression and preceded exit from the cell cycle, as shown by time-course analysis (Figure 2e). Furthermore, the ERK2 downregulation was dose-dependent (Figure 2f). Similar results were obtained by analyzing the phosphorylated forms of both ERK1 and ERK2 proteins by a phosphospecific Ab, indicating that also the ERK1 protein, which is basically expressed at lower levels in these cells, behaves similar to the ERK2 (Figure 2f). Functional analyses of ERK2 activity showed that the reduced levels of ERK2 expression and phosphorylation were associated with a strong reduction in the total ERK2specific kinase activity, as measured in vitro on the myelin basic protein substrate (MBP), and as evaluated in vivo by analyzing the expression of the downstream target of ERK2, cyclin D1 (Figure 2g). Comparable results were obtained when $\mathrm{C} 2 \mathrm{C} 12$ cells were transformed with a constitutively activated form of MEK1/MAPKK, MEK1 $1^{(217-221)}{ }^{3}$ and infected with Adp53 (Online Supplemental Material), indicating that p53 interferes with the Ras/MAPK cascade at level that is not upstream of MEK1.

Altogether, these results show that also in cells with a constitutively activated Ras/MAPK pathway, p53-mediated growth arrest is associated with a strong ERK2 inactivation.

\section{ERK2 inactivation is specific of p53-induced growth arrest}

The timing of ERK2 downregulation we observed after p53 overexpression indicates that it precedes growth arrest rather than being a consequence of it. To confirm this hypothesis, Ras-transformed cells were growth arrested by stimuli different from p53 activation. Specifically, C2-Ras and $\mathrm{NIH}$ Ras cells were either induced to overexpress the cyclin/cdk complex inhibitor p21 WAF1, a downstream effector of p53 growth suppression, ${ }^{20}$ by infection with the recombinant adenovirus Adp21, or treated with the mitotic inhibitor nocodazole. The effects of these two agents on the cell cycle, as well as that of Adp53 infection, were assessed by cytofluorimetric analyses. G2/M accumulation was found after each treatment (Figure $3 \mathrm{a}$ and $\mathrm{c}$ ); however, the ERK2 downregulation could be observed in the p53-overexpressing cells but not in the p21 $21^{\text {WAF } 1}$-overexpressing or the nocodazole-treated cells (Figure $3 b$ and $d$ ). These results indicate that ERK2 is a specific target of p53-induced growth suppression and not a consequence of the cell cycle arrest. Furthermore, they indicate that ERK2 inactivation is independent of the p53 mediator p2 $1^{\mathrm{WAF} 1}$.

\section{p53 inactivates ERK2 by promoting its cleavage through a caspase-3-like activity}

To investigate the biochemical mechanism responsible for p53-mediated ERK2 inactivation, we first evaluated erk2 mRNA levels by Northern blot hybridization. No difference was found between control and Adp53-infected C2-Ras cells (Figure 4a), indicating that p53 does not repress the erk2 gene



b

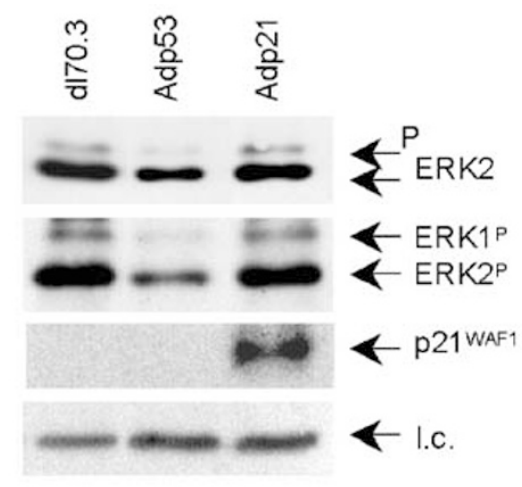

C

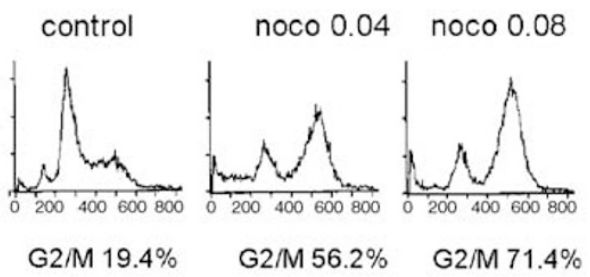

d

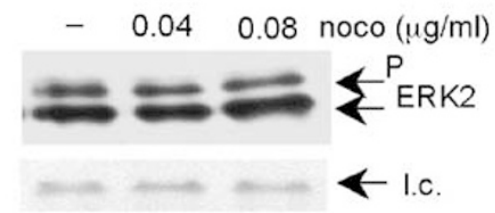

Figure 3 ERK2 is not downregulated in p21 ${ }^{\text {WAF1 }}$ - or nocodazole-arrested cells. (a) $\mathrm{NIH}$-Ras cells infected with the indicated viruses at $1 \times 10^{3} \mathrm{~m}$.o.i. were stained $72 \mathrm{~h}$ p.i. with $\mathrm{PI}$ and analyzed by flow cytometry. Cell cycle profiles and percentages of cells in the different phases of the cell cycle are reported. (b) WB analyses of total ERK2 and phosphorylated ERK1 and ERK2 on TCEs from cells analyzed in (a). The expression of the exogenous human $\mathrm{P} 21^{\mathrm{WAF} 1}$ protein was assessed by WB with anti-human p21 ${ }^{\text {WAF1 }} \mathrm{Ab}$. (c) Proliferating C2-Ras cells were treated for $8 \mathrm{~h}$ with the indicated amounts of nocodazole and subjected to cell cycle analyses. The percentages of cells accumulated in the G2/M phase of the cell cycle are indicated. (d) WB analyses for total ERK2 protein on TCEs from cells analyzed in (c)

at the transcriptional and RNA stability levels. Secondly, we excluded a p53-induced activation of MAPK-specific phosphatases by treating Adp53-infected C2-Ras cells with the tyrosine-phosphatase inhibitor sodium orthovanadate (data not shown) or transducing the C2-Ras cells with the phosphatase-resistant D319N mutant (Online Supplemental Material). Instead, pulse-chase experiments showed that p53 


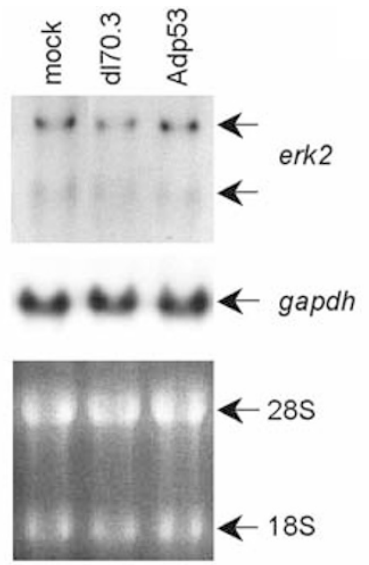

b

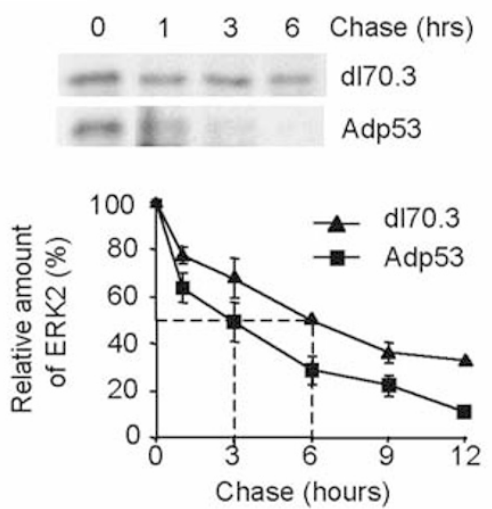

f

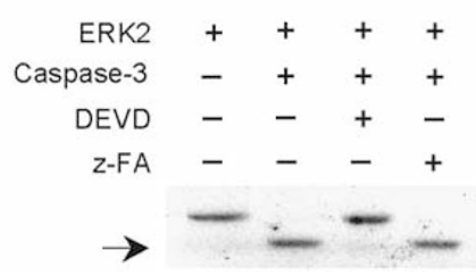

C



g

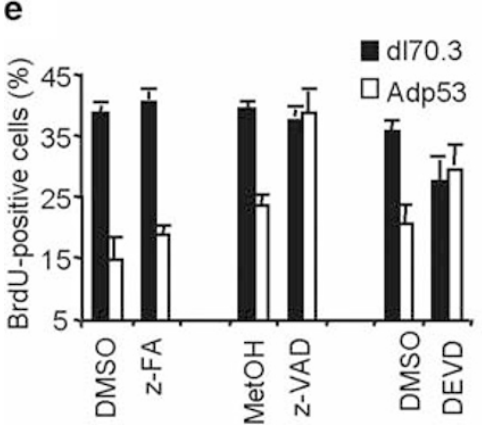

h

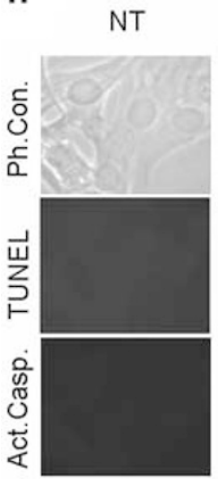

Staurosporin

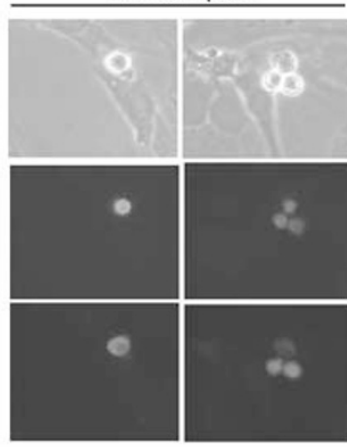

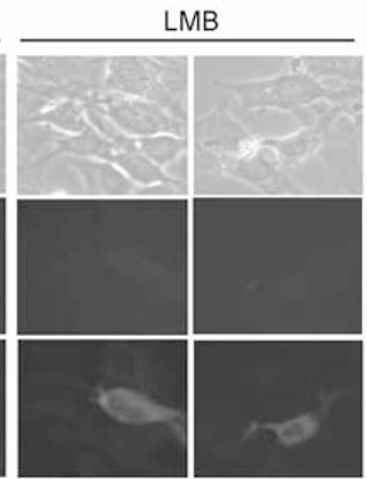

Figure 4 p53 reduces the half-life of ERK2 by caspase-mediated cleavage. (a) Northern blot hybridization of Adp53-infected C2-Ras cells. Total RNA was extracted from the indicated cells $48 \mathrm{~h}$ p.i. and hybridized with erk2- and gapdh-specific probes. The two erk2 transcripts are indicated. (b) Pulse chase of Adp53-infected C2-Ras cells. At $48 \mathrm{~h}$ p.i., C2-Ras cells were pulse labeled with $\left[{ }^{35} \mathrm{~S}\right]$ methionine, chased and harvested at the indicated times. ERK2 protein was immunoprecipitated from equal amounts of TCEs, resolved on SDS-PAGE and subjected to fluorography. A longer exposure of the Adp53-infected samples is reported for comparison with the dl70.3 control at the 0 time point. ERK2 levels were quantified by densitometry. The data plotted are means \pm S.D. of three independent experiments. (c) WB of ERK2 protein in Adp53-infected C2-Ras cells. At $48 \mathrm{~h}$ p.i., cells were treated for $16 \mathrm{~h}$ with the proteasome inhibitor lactacystin (LC), the caspase inhibitor $\mathrm{z}$-VAD, the serine-protease inhibitor PMSF, or lysosomal protease inhibitor cloroquine (CQ) before WB. (d) At $72 \mathrm{~h} \mathrm{p.i.,} \mathrm{infected} \mathrm{C2-Ras} \mathrm{cells} \mathrm{were} \mathrm{treated} \mathrm{for} 8 \mathrm{~h}$ with z-VAD or its solvent. ERK2 protein was immunoprecipitated from TCEs and tested for kinase activity on MBP. (e) Caspase inhibitors restore cell proliferation in p53-arrested cells. Infected C2-Ras cells were treated at $48 \mathrm{~h}$ p.i. with the indicated inhibitors for $16 \mathrm{~h}$ and analyzed for BrdU incorporation by indirect immunofluorescence. Data reported are means \pm S.D. of four independent experiments. z-FA is the caspase inhibitor negative control. (f) In vitro cleavage of ERK2 protein by recombinant caspase-3. In vitro-translated, radiolabeled ERK2 protein was incubated for $1 \mathrm{~h}$ with $200 \mathrm{ng}$ of purified recombinant caspase-3 in the presence or absence of the caspase-3 inhibitor DEVD or in the presence of the negative control z-FA, and analyzed by SDS-PAGE. The arrow indicates the caspase-3 cleavage product of ERK2. (g) In vivo caspase activity in infected C2-Ras cells. At $36 \mathrm{~h} \mathrm{p.i.,} \mathrm{FAM-DEVD-FMK} \mathrm{was} \mathrm{added} \mathrm{to} \mathrm{the} \mathrm{cell} \mathrm{culture} \mathrm{for} 1 \mathrm{~h}$ to allow its irreversible binding with activated caspase-3 and caspase-3-like, and revealed by cytofluorimetric analyses. Apoptotic cells ( $<5 \%$ by TUNEL in both control and Adp53-infected cells) were excluded by PI staining. (h) In vivo detection of active (cleaved) caspase-3. C2-Ras cells were treated with LMB as in Figure 1e, or with staurosporin to induce apoptosis, fixed and double stained with anti-cleaved caspase-3 Ab (red fluorescence) and TUNEL (green fluorescence)

overexpression reduces the ERK2 half-life from 6 to $3 \mathrm{~h}$ (Figure 4b), indicating that p53 can promote ERK2 degradation.
To investigate the p53-mediated reduction of ERK2 halflife, Adp53-infected C2-Ras cells were treated with different protease inhibitors. We found that z-VAD caspase inhibitor 
was able to restore completely ERK2 expression and phosphorylation levels (Figure 4c) as well as the ERK2 kinase activity (Figure 4d). Furthermore, z-VAD treatment could rescue cell proliferation in p53-arrested cells (Figure $4 \mathrm{e}$ ), strongly indicating that p53 promotes a caspase-mediated ERK2 cleavage that contributes to growth arrest.

Recently, it was shown that p53-induced caspase-3-like activity promotes $\mathrm{pRb}$ and AKT/PKB cleavage in apoptotic cells. ${ }^{21,22}$ Thus, we evaluated whether ERK2 can be a caspase-3 target by an in vitro cleavage assay. As shown in Figure $4 \mathrm{f}$, recombinant caspase- 3 can cleave an in vitrotranslated ERK2 protein and yield a major product of approximately $39 \mathrm{kDa}$. This cleavage was prevented by the caspase-3 inhibitor DEVD that was also able to rescue DNA synthesis in the presence of overexpressed p53, while the zFA negative control had no effect (Figure $4 \mathrm{e}$ and $\mathrm{f}$ ). We could not consistently detect the $39 \mathrm{kDa}$ polypeptide in in vivo experiments; however, lysates from growth-arrested cells could easy produce this digestion product when engaged in a cleavage test (see below; Figure 6b).

Nonapoptotic functions of caspases have recently been described. $^{23}$ To confirm the in vivo presence of caspase activity in p53 growth-arrested cells, we employed the fluorescent inhibitor FAM-DEVD-FMK that irreversibly binds active caspase-3 and -3-like in cultured cells. A PI staining of nonfixed cells was utilized to exclude the eventual small number of dead cells. The absence of apoptosis was confirmed by measuring cell viability through trypan blue exclusion during the next $48 \mathrm{~h}$ (data not shown). As shown in Figure $4 \mathrm{~g}$, a positive fluorescence was found in Adp53infected, PI-negative cells, indicating the presence of a caspase-3 or -3-like activity induced by p53 in nonapoptotic cells. In addition, double immune-staining with anti-active caspase-3 Ab and TUNEL was performed on C2-Ras cells treated with LMB to induce p53-mediated growth arrest. As positive control, the same cells were treated with staurosporin to induce apoptosis. Consistent with the previous result, active caspase- 3 molecules were found in TUNEL-negative, LMB-treated cells (Figure 4h).

Altogether, these results show that $p 53$ inactivates ERK2 by promoting its cleavage through a caspase activity, and suggest that caspase-3 or -3-like are involved. Furthermore, they indicate that the ERK2 cleavage contributes to the p53mediated growth arrest.

\section{ERK2 cleavage is required for p53 to inhibit cell proliferation}

To further investigate the requirement for ERK2 digestion in p53-mediated growth arrest, a caspase-resistant ERK2 mutant was generated. Analysis of the ERK2 protein sequence revealed, among several potential cleavage sites for caspase-3, the sequence ELDD (residues 332-335 in mouse and 334-337 in human ERK2) predicted to yield a fragment compatible with that observed in the in vitro assay. The aspartic acid at position P1 of the mouse ERK2 was replaced with an alanine to abolish the putative cleavage site. ${ }^{24}$ Resistance of this ERK2 mutant (D335A) to caspase-3 activity was first tested in in vitro cleavage assay. As shown in
Figure 5a, the mutant showed a partial resistance to caspase3 proteolysis as compared to the wild-type ERK2 (wtERK2) protein. Two other putative caspase sites (i.e., IVQD at position 101-104 and LHRD at 144-147) were mutated. However, they were not resistant to in vitro caspase activity (data not shown).

To evaluate the biochemical and biological activities of the D335A mutant in vivo, C2-Ras cells were transfected with expression vectors encoding either wtERK2 or mutant (D335A) HA-tagged proteins before infection with adenoviruses. The cells were then analyzed for expression of the exogenous proteins and their relative kinase activity. Only a mild reduction in the expression levels of the D335A was found after Adp53 infection, compared to wtERK2 (Figure 5b, upper panel), indicating that the cleavage resistance of this ERK2 mutant is maintained in vivo. Furthermore, the kinase activity of D335A was not repressed by p53 overexpression (Figure 5b, lower panel), demonstrating that p53 inhibits ERK2 kinase activity by promoting its cleavage. To evaluate whether this type of ERK2 inactivation contributes to the induction of p53-mediated growth arrest, BrdU incorporation of D335A-transfected C2-Ras cells was measured after adenoviral infection. The expression of the caspase-resistant D335A was able to inhibit the p53-induced growth arrest (Figure 5c). Furthermore, the cell cycle profile of C2-Ras cells was analyzed upon transient cotransfection with wtERK2, D335A, or the empty pCMV plasmid, and a GFP-encoding vector, and then infected with Adp53. Consistent with the BrdU-incorporation data, in the GFP-positive populations, an increase in the percentage of cells in the $S$ phase of the cell cycle and a reduction of the G2/M phase was present in the D335A-transfected cells and, to a much less extent, in the wtERK2-transfected cells. As control, no difference was found among the GFP-negative cell populations (Figure $5 \mathrm{~d}$ ). Taken together, these results show that the expression of the caspase-resistant D335A mutant interferes with the p53induced growth arrest.

It was recently found that oncogenic Ras signaling through MAPK cascade can upregulate MDM2 and consequently inhibit p53 activity. ${ }^{5}$ Consistent with these data, a strong upregulation of MDM2 was found in C2-Ras transformed cells compared to their nontransformed counterparts (Figure 5e). However, no further increase in MDM2 levels was observed in C2-Ras cells upon overexpression of either wtERK2 or D335A (Figure 5f), ruling out the possibility that exogenous expression of the ERK2 proteins could further upregulate MDM2 and restore cell proliferation by blocking p53 activity through this pathway.

Taken together, these results provide strong evidence that the ERK2 cleavage is required for p53 to induce cell cycle arrest in Ras-transformed cells.

\section{Inhibition of caspase activity interferes with ADR- and LMB-induced cell cycle arrest}

As described above, the ERK2 downregulation was associated with p53-induced cell cycle arrest in nontransformed C2C12 cells upon ADR treatment or in C2-Ras cells upon LMB treatment. Based on our subsequent findings (i.e., p53-induced, caspase-mediated degradation of ERK2), 


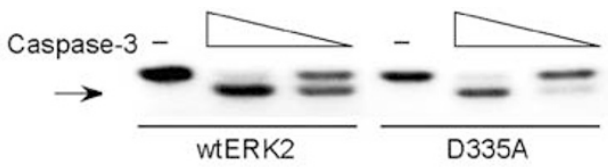

b

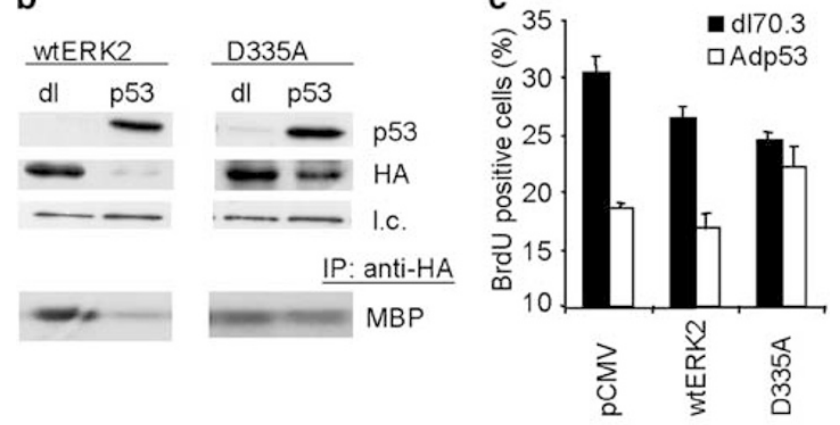

d

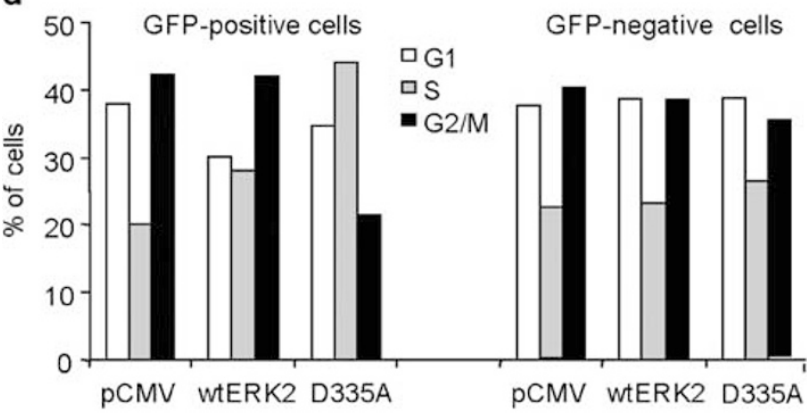

e

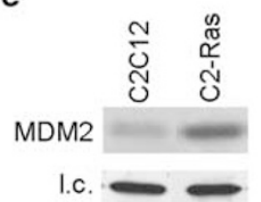

f



Figure 5 Caspase-resistant ERK2 mutant impairs the p53-induced growth arrest. (a) In vitro-translated radiolabeled wtERK2 and D335A mutant were exposed to decreasing amounts of purified caspase-3 (20 and $2 \mathrm{ng})$ for $1 \mathrm{~h}$ and analyzed by SDS-PAGE. The arrow indicates the cleavage product. (b) The D335A mutant is resistant to caspase-mediated cleavage in vivo. C2-Ras cells were transiently transfected with $1 \mu \mathrm{g}$ of plasmids encoding for the HA-tagged wtERK2 or D335A mutant proteins. At $24 \mathrm{~h}$ post-transfection, cells were re-plated for infection with d170.3 or Adp53. The two infected populations derive from the same transfection to reduce experimental variability. One dish from each infection was analyzed for BrdU incorporation $48 \mathrm{~h}$ later (see (c)), and the other was used for WB and kinase activity. The transfected ERK2 proteins were analyzed with anti-HA antibody. (c) Interference with ERK2 cleavage impairs the p53-induced growth arrest. BrdU incorporation was evaluated at the same time points reported in (b). (d) C2-Ras cells were transiently cotransfected with PCMVwtERK2, pCMV-D335A mutant or the empty vector, and a GFP-carrying vector ( $5: 1$ molar ratio). At $24 \mathrm{~h}$ post-transfection, cells were infected with Adp53 virus and analyzed by flow cytometry $48 \mathrm{~h}$ later. DNA content analyses were performed separately on the GFP-positive (transfected cells, 25\% of the total population) and GFP-negative (nontransfected) cell populations. The percentage of cells in the different phases of the cell cycle is reported. Data represent one indicative experiment of three independent transfections performed. (e) WB of MDM2 protein on TCEs from parental and v-Ha-Ras-transformed C2C12 myoblasts. (f) WB of the indicated proteins in C2-Ras cells. Transfected populations were enriched by a $48 \mathrm{~h}$ selection with puromycin ( $~ 90 \%$ of HA-positive cells by indirect immunofluorescence with anti-HA Ab; data not shown) before WB analyses we asked whether the described mechanism is involved in the p53-mediated growth arrest in these more physiological conditions. We first demonstrated the presence of caspase activation in ADR-arrested $\mathrm{C} 2 \mathrm{C} 12$ cells by indirect immunofluorescence with FAM-z-VAD-FMK (Figure 6a). In addition, we verified the presence of an ERK2 cleavage activity in the TCEs from ADR-arrested $\mathrm{C} 2 \mathrm{C} 12$ cells by their incubation with a recombinant ERK2 protein. The expected $39 \mathrm{kDa}$ digestion product was found and its generation was inhibited by z-VAD and DEVD but not by z-FA negative control (Figure 6b). To assess the functional relevance of the ERK2 degradation, C2C12 cells were pretreated with $\mathrm{z}-\mathrm{VAD}$ for $18 \mathrm{~h}$ before $\mathrm{ADR}$ administration. As shown in Figure $6 c$ and d, the caspase inhibitor was able to interfere with the ADR-induced ERK2 cleavage in vivo and completely restore DNA synthesis.

To ensure that this mechanism of p53-mediated growth arrest is not confined to mouse cells, a series of human cell lines with different endogenous $p 53$ gene status were used (i.e., wtp53-carrying RKO, MCF-7, and U87MG, p53-null H1299, mutant p53-carrying T98G and U373MG). Caspase interference was obtained by DEVD pretreatment before ADR administration. As described above, the $\mathrm{IC}_{50}$ of $\mathrm{ADR}$ was calculated and used for each cell line to ensure the absence of apoptosis (data not shown). Time-course analyses of thymidine incorporation showed a consistent increase in DNA synthesis in the DEVD-treated cells compared to their relative, untreated controls (Figure 6e, upper panel). Most importantly, this effect was present only in the wtp53-carrying cells further demonstrating its p53 dependency (Figure 6e, lower panel). Moreover, DNA content analyses of RKO cells showed a partial depletion of the G1 fraction in the DEVD pretreated cells compared to the relative control (Figure 6f; data not shown). Interestingly, the depletion was not complete, as observed in the p53-defective cells, in which all the p53dependent pathways of G1 arrest, including the p21 WAF1 dependent one, are missing, showing that ERK2 degradation contributes to the G1 block.

The functional results were confirmed at the molecular levels by employing RKO and RKO-p53i cells in which p53 expression was downregulated by stable transfection of pSUPER-p53 vector ${ }^{25}$ (Figure 6g, p53-panel). ADR treatment of these cells downregulated ERK2 only in parental, wtp53carrying RKO cells, and this effect was reverted by DEVD pretreatment (Figure 6g, ERK2-panel).

Since we originally observed an ERK2 downregulation also in the LMB-induced growth arrest, we evaluated the effects of the caspase inhibitors on LMB-treated, Ras-transformed C2LX and C2-DD cells. As shown in Figure 6h, the caspase inhibitors were able to recover partially the LMB-induced inhibition of DNA synthesis in C2-LX-Ras cells. Interestingly, the recovery levels obtained in C2-LX-Ras cells reached the amounts of DNA synthesis comparable to those measured on C2-DD-Ras cells, indicating that the caspase inhibitors can completely rescue the p53-dependent component of the LMBinduced growth arrest. These results show that the p53mediated LMB-induced growth arrest operates through caspase activity.

Overall, these data demonstrate a functional role for ERK2 cleavage by caspases also in p53-dependent DNA damage or LMB-induced growth arrest. 


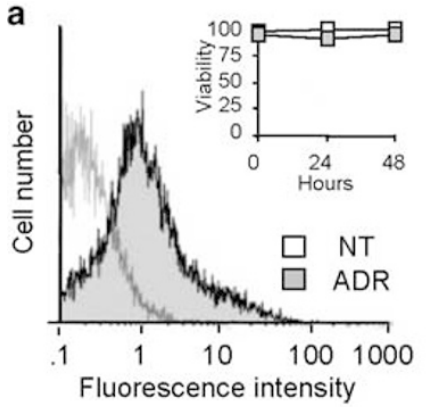

b

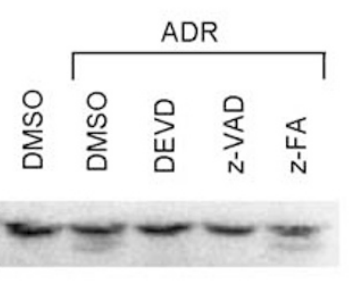

C

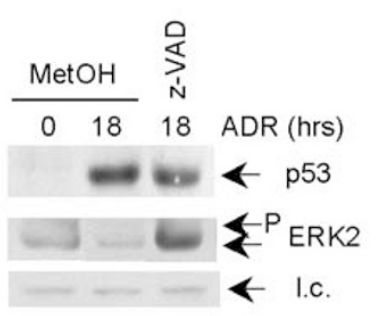

d



e

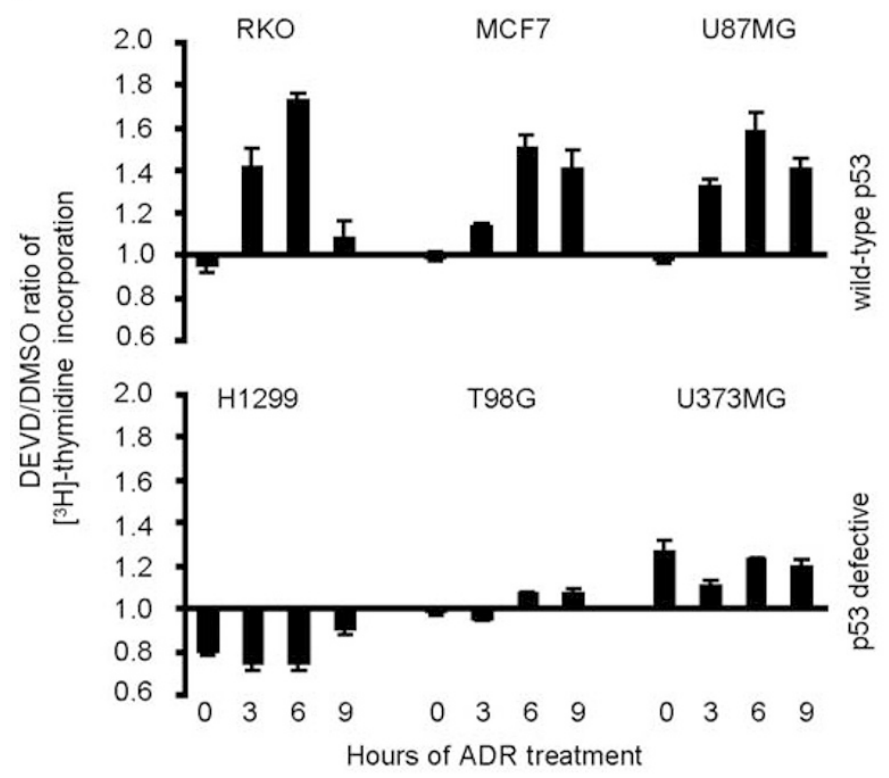

f

RKO (wtp53)

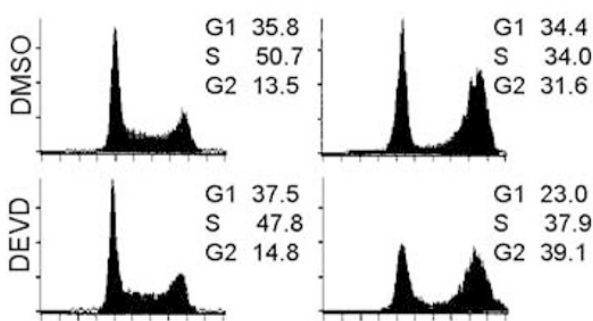

H1299 (p53 null)

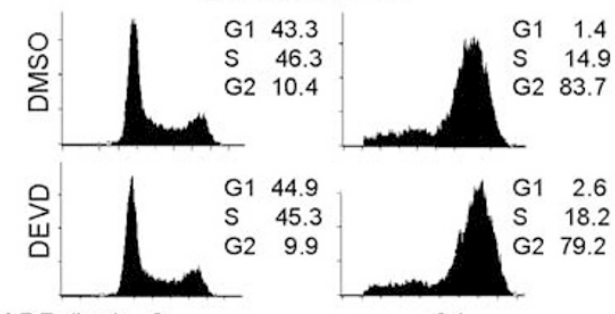

ADR (hrs) 0
24 g

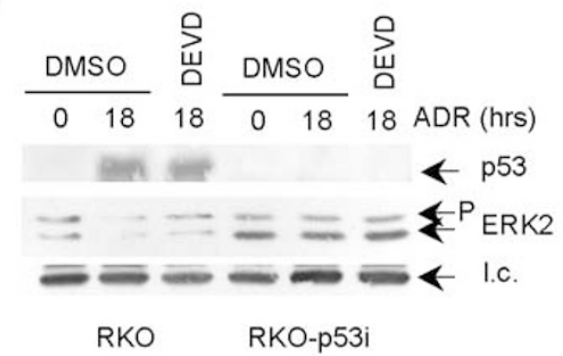

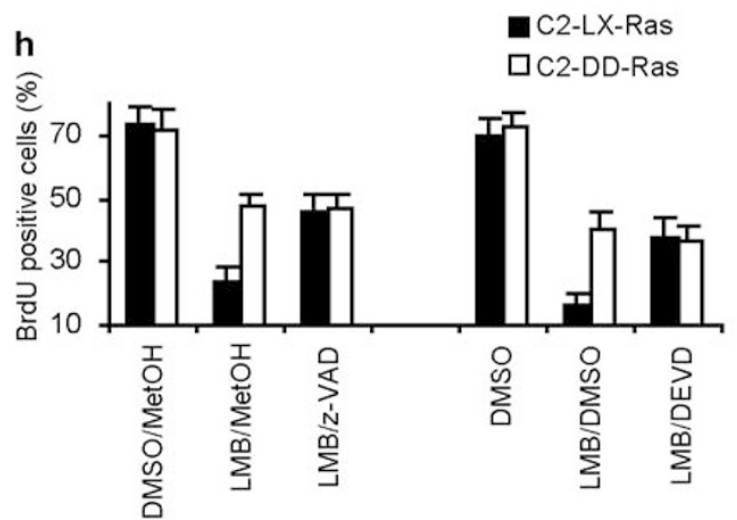

Figure 6 Caspase inhibitors interfere with ADR-and LMB-induced growth arrest. (a) In vivo caspase activity in C2C12 cells treated with $0.9 \mu \mathrm{M}$ ADR for $18 \mathrm{~h}$. Cells were incubated with FAM-Z-VAD-FMK and analyzed as in Figure 4f. Only PI-negative, nonapoptotic cells were analyzed. Cell viability was measured by trypan blue exclusion upon ADR release during the next $48 \mathrm{~h}$ to guarantee the absence of death. NT stands for not treated cells. (b) TCEs from ADR-treated cells (100 $\mu \mathrm{g} / \mathrm{sample}$ ) were incubated for $90 \mathrm{~min}$ at $37^{\circ} \mathrm{C}$ with in vitro-translated ERK2 protein in the absence or presence of the indicated caspase inhibitors. The arrow indicates the $39 \mathrm{kDa}$ cleavage product of ERK2. (c) C2C12 cells were treated with ADR for $18 \mathrm{~h}$ in the presence of z-VAD or its solvent. Proteins from TCEs were analyzed by WB for p53 and ERK2 expression. (d) $\mathrm{C} 2 \mathrm{C} 12$ cells were pretreated for $14 \mathrm{~h}$ with $\mathrm{z}-\mathrm{VAD}$ or with its solvent, before ADR treatment. BrdU incorporation was detected by indirect immunofluorescence. Means \pm S.D. of three independent experiments are presented. (e) The indicated cells were treated with $\mathrm{ADR}$ at their relative $\mathrm{IC}_{50}(0.5 \mu \mathrm{M}$ for U87MG; $0.4 \mu \mathrm{M}$ for MCF-7, H1299, T98G, and U373MG; $0.2 \mu \mathrm{M}$ for RKO) for the indicated times in the presence of DEVD or its solvent DMSO. [ ${ }^{3} \mathrm{H}$ ]thymidine incorporation was measured in quadruplicate. Means \pm S.E. of DEVD/DMSO ratios of three independent experiments are reported. (f) The same cells were treated as in (e) for $24 \mathrm{~h}$ and DNA content analyzed by flow cytometry after PI staining. Graphics and relative percentages of cells in different phases of the cell cycle are reported for RKO and H1299 cells. (g) The indicated cells were treated with ADR for $18 \mathrm{~h}$ in the presence of DEVD or its solvent. Proteins from TCEs were analyzed by WB for p53 and ERK2 expression. (h) C2-LX-Ras and C2-DD-Ras transformed cells were pretreated for $16 \mathrm{~h}$ with z-VAD, DEVD, or their relative solvents before the addition of LMB. Means \pm S.D. of three independent experiments of BrdU incorporation are reported 


\section{Discussion}

\section{ERK2 is a novel target of the p53 growth suppression activity}

A variety of cellular stresses can activate the p53 oncosuppressor protein that, in turn, promotes different biological outcomes. $^{26}$ Several genes were found to be targets of p53 during these events. Some of these gene products were shown to be p53 mediators in cell cycle control, others in apoptosis. ${ }^{27}$ In the current study, we present a series of molecular and functional data showing that ERK2 is a novel target of the p53 growth suppression activity. ERK2 inactivation was observed in different experimental conditions, in which only growth arrest was present while no apoptosis was induced, including ADR-induced DNA damage, p53 nuclear accumulation by LMB, and p53 overexpression by Adp53 infection. In each case, interference with ERK2 inactivation restored cell proliferation.

In wtp53-carrying cells, ADR-induced DNA damage is known to block both G1-S and G2-M transition while direct p53 inactivation results in complete $\mathrm{G} 1$ depletion. ${ }^{28}$ In murine and human wt53-carrying cells, we showed that the impairment of the ERK2 cleavage by caspase inhibitors interfered with the ADR-induced G1 arrest, slowing down the exit from the cell cycle and determining a partial depletion of the G1 phase. These results indicate that the ERK2 cleavage participates in the p53-mediated mechanisms of G1 arrest.

In the C2-Ras cells, p53 overexpression induced only an accumulation in the $\mathrm{G} 2 / \mathrm{M}$ phase of the cell cycle. This accumulation was overcome by treatment with caspase inhibitors or by overexpression of caspase-resistant D335A mutant suggesting that p53-mediated ERK2 cleavage can also contribute to the G2/M arrest. Interestingly, in addition to its definite role in the G1-S transition, the Ras/MAPK cascade was recently shown to regulate the G2-M transition ${ }^{29}$ and mediates the commitment for completion of the next cell cycle by inducing cyclin D1 expression when the cells are in the G2 phase. ${ }^{30}$ Our finding that p53 can also induce growth arrest in G2 phase by inhibiting ERK2 activity and cyclin D1 expression is in good agreement with this newly identified role of Ras/ MAPK.

Interestingly, we had previously observed that the cell cycle accumulation in G2/M induced by p53 overexpression in C2Ras and NIH-Ras cells is not accompanied by any measurable increase in p2 $21^{\text {WAF1 }}$ mRNA or protein. ${ }^{31}$ Furthermore, we showed that ERK2 inactivation is independent of p21 WAF1, suggesting that p53 can arrest the cells in the G2/M phase through different pathways.

\section{p53 inactivates ERK2 through a nonapoptotic caspase activity}

By studying the mechanism through which p53 inactivates ERK2, we found that in Ras-transformed C2C12 cells p53 overexpression halves the ERK2 half-life from 6 to $3 \mathrm{~h}$ indicating that p53 acts on ERK2 stability. Interestingly, we also found that, following Ras transformation of $\mathrm{C} 2 \mathrm{C} 12$ cells, the half-life of the ERK2 protein increased from 3 to $6 \mathrm{~h}$ (unpublished data), suggesting that oncogenic Ras activity not only increases ERK2 phosphorylation, but also influences ERK2 stability. We have identified in a caspase-mediated cleavage the mechanism of ERK2 degradation. Indeed, we found that (i) specific caspase inhibitors recover both biochemical and functional activities of ERK2 in the presence of p53 activation; (ii) caspase-3 or -3-like activity is present in Adp53-infected, LMB- and ADR-treated C2-Ras and C2C12 cells; (iii) the caspase-resistant D335A mutant interferes with p53-induced growth arrest.

We could not consistently detect the $39 \mathrm{kDa}$ product of the ERK2 caspase cleavage in vivo. The hurdle in detecting cleavage products in vivo is not unusual even during apoptosis. ${ }^{22,32}$ Indeed, the appearance of proteolytic products is mainly correlated with the production of active and stable enzymes from pro-enzymes (e.g., caspase cascade activation). Instead, our data show that the ERK2 cleavage has an inhibitory effect on its activity, supporting the existence of a subsequent rapid degradation mechanism of the $39 \mathrm{kDa}$ polypeptide.

Activation of caspase-3 or -3-like can mediate p53dependent $\mathrm{pRB}^{21}$ and $\mathrm{AKT} / \mathrm{PKB}^{22}$ cleavage during apoptosis. The data reported here show that the ERK2 protein is a new target of the caspase-3-like activity induced by the p53 oncosuppressor. Furthermore, our results demonstrate an additional role for caspases in cell cycle arrest. Recently, caspase activities were found to be involved in biological events different from apoptotic death, such as the negative control of erythroid differentiation ${ }^{23}$ and the modulation of the MDM2 and MDMX proteins in nonapoptotic cells. ${ }^{33,34}$ Our results add evidence for a novel role of caspases, strengthening the concept that this complex net of proteases has been evolutionarily selected to accomplish multiple, different tasks in addition to cell suicide. However, whether the same caspases are involved in apoptotic and nonapoptotic functions through different mechanisms of activation or specificity, or whether caspase-like activities different from the classical apoptosis-associated caspases are responsible for these newly described, nonapoptotic functions need to be evaluated. Of note, we found that p53 is still able to inactivate ERK2 in caspase-3-deficient MCF-7 cells (unpublished data) and that the DEVD treatment rescues the p53-induced growth arrest in the same cell line (Figure 6e). These data support the hypothesis that caspase-3-like activities or redundant effects by other caspases could be involved in ERK2 cleavage.

\section{p53 counteracts the Ras/MAPK cascade}

In the past few years, it was found that the Ras/MAPK cascade modulates p53 activity through activation or repression pathways involved in tumor suppression or transformation. ${ }^{4-6}$ Furthermore, it was also observed that the activation of the Ras/MAPK pathway is involved in the p53-dependent apoptosis in response to DNA damage. ${ }^{9,35}$ Here we show that p53 can directly counteract the Ras/MAPK pathway by promoting a caspase-mediated ERK2 cleavage. In particular, upon DNA damage, we have found an early increase of the ERK2 expression and phosphorylation followed by a strong downregulation. Based on these findings, it can be hypothesized that after an initial activation of the Ras/MAPK pathway, which predisposes cells to respond to stress signals and 
eventually die by apoptosis, a subsequent inhibition of this pathway is required in the case the cells choose to survive (Figure 7a). This model might account for the reversibility of the cellular response to different stresses, such as those producing a transient growth arrest for a repairable DNA damage. Consistent with this, following expression of different levels of exogenous p53 in Ras-transformed cells, a sustained activation of ERK2 is associated with high p53 expression levels and apoptosis, while inhibition of ERK2 activity is found in those cells expressing low levels of p53 and undergoing growth arrest (unpublished data). However, whether this different ERK2 modulation is involved in a switch between apoptosis and growth arrest following DNA damage needs a further extensive evaluation.

During tumor transformation, oncogenic Ras was shown to activate the PI3K-AKT/PKB pathway that interferes with p53dependent apoptosis ${ }^{36}$ and/or to repress p53 function by transcriptionally activating the p53 inhibitor MDM2. ${ }^{5}$ In the stepwise development of colon cancer, Ras mutations precede p53 mutations. ${ }^{37}$ Thus, it has been proposed that oncogenic Ras can suppress the wtp53 activity during the early steps of tumor development through the abovementioned mechanisms. However, p53 mutations and loss of heterozygosity eventually take place despite the activation of these anti-p53 factors, suggesting the presence of residual wtp53 oncosuppressing activities. Indeed, the finding that p53 can directly counteract the Ras/MAPK pathway might create a negative loop with ERK2 and, consequently, suppress the p53-dependent and -independent oncogenic functions of

a DNA damage

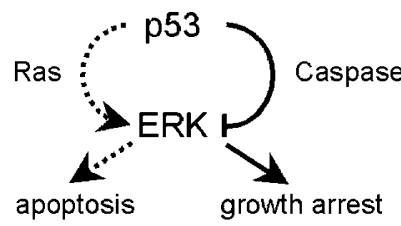

b

neoplastic transformation

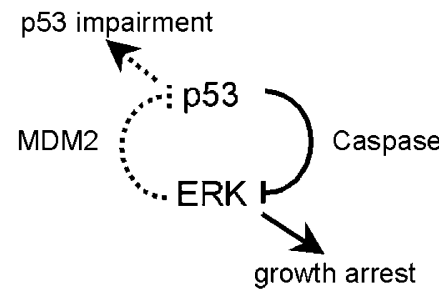

Figure 7 Model for the regulation of Ras/MAPK pathway by p53. (a) ERK regulation by $\mathrm{p} 53$ during DNA damage. Following DNA damage, a persistent ERK activation by p53 drives the cells to apoptotic death (i.e., irreversible outcome). In the presence of a repairable damage, a p53-mediated switch to ERK inactivation drives the cells to growth arrest (i.e., reversible outcome). (b) ERK/p53 crossed regulation in neoplastic transformation. Ras mutations promote p53 impairment through ERK-mediated activation of the p53 inhibitor MDM2. p53 can counteract this impairment through the caspase-mediated cleavage of ERK. This activity might be involved in the selective pressure for p53 mutations in tumor development
MDM2 (Figure 7b). This model is consistent with the later appearance of $\mathrm{p} 53$ mutations. Moreover, the findings reported here together with our previous observations showing that p53 can cleave AKT/PKB and induce apoptosis in colon carcinoma cells upon re-expression of the $\alpha 6 \beta 4$ integrin $^{22}$ strongly suggest that p53 can counteract both mechanisms of Rasmediated inhibition of p53 oncosuppressing activities.

In conclusion, we have found a new mechanism of p53mediated growth arrest, which requires a caspase-mediated cleavage of the ERK2 protein. This finding strongly indicates that $\mathrm{p} 53$ can directly counteract the Ras/MAPK cascade. This function might have important implications in p53 tumor suppressing activities, as well as in the reversibility of the cellular responses to different stress conditions, at least in the cases associated with an activation of the Ras/MAPK pathway.

\section{Materials and Methods}

\section{Cell culture conditions and treatments}

C2-Ras, NIH-Ras, F5-Ras, C2-LX-Ras, and C2-DD-Ras cell lines were obtained by infecting $\mathrm{C} 2 \mathrm{C} 12$ murine myoblasts, NIH3T3 murine fibroblasts, primary fibroblasts from $\mathrm{p} 53^{-1-}$ and $\mathrm{p} 53^{+1+}$ mice, C2-LX, and C2-DD cells, respectively, with the replication-competent, v-Ha-rasexpressing murine sarcoma virus (MSV). ${ }^{38}$ These cells were utilized in few passages after infection to avoid the acquirement of genetic changes during the passages.

The $I_{50}$ values (i.e., the drug concentration that inhibits the proliferation rate to $50 \%$ ) for ADR were measured as described. ${ }^{39}$

LMB was kindly provided by Barbara Wolff, Novartis and was used at $10 \mathrm{nM}$ for $18 \mathrm{~h}$. Protease inhibitors were used for $16 \mathrm{~h}$ at the following concentrations: $10 \mu \mathrm{M}$ lactacystin proteasome inhibitor (Biomol), $2 \mathrm{mM}$ phenylmethylsulfonyl fluoride (PMSF) serine-protease inhibitor, $100 \mu \mathrm{M}$ chloroquine lysosome inhibitor (Sigma), 40 or $100 \mu \mathrm{M}$ Z-Val-Ala-DL-Aspfluoromethylketone (Z-VAD-fmk) pan-caspase inhibitor, 6 or $60 \mu \mathrm{M} Z$ ZAsp(OMe)-Glu(OMe)-Val-Asp(OMe)-fluoromethylketone (DEVD-fmk) caspase-3 inhibitor (also inhibits caspase-6, -7, -8, and -10), $100 \mu \mathrm{M}$ Z-PheAla-fluoromethylketone (z-FA-fmk) negative control for caspase inhibitors (all from Calbiochem). MetOH and DMSO solvents were used as control.

\section{Recombinant adenoviruses and adenoviral infection}

The recombinant adenoviruses employed in this study belong to the E1E3-deleted type of vectors, and are the following: Adp53 and Adp21 carrying the human wtp53 and p21Waf1 cDNAs, respectively, under the control of the CMV promoter; the insert less control dl70.3. Virus stocks and titration were performed on 293 cells as described. ${ }^{40}$ For adenoviral infection, approximately $1.2 \times 10^{5}$ cells were plated in $35 \mathrm{~mm}$ Petri dishes and infected at the indicated multiplicity of infection (m.o.i.), by $1 \mathrm{~h}$ incubation at $37^{\circ} \mathrm{C}$ in the presence of a thin layer of medium. Medium alone was used for mock infections.

\section{Western blot analysis}

Cells were lysed in RIPA buffer ( $50 \mathrm{mM}$ Tris- $\mathrm{HCl}$ pH 8, $150 \mathrm{mM} \mathrm{NaCl}, 0.5 \%$ sodium deoxycholate, $0.1 \%$ SDS, $1 \%$ NP40, 1 mM EDTA) supplemented with protease-inhibitor mix (Roche), $5 \mathrm{mM}$ sodium orthovanadate, $50 \mathrm{mM}$ $\mathrm{NaF}$, and $5 \mathrm{mM} \mathrm{EGTA}$ (Sigma). Equal amounts of proteins were separated 
by electrophoresis on 12.5\% SDS-PAGE (acrylamide/bis-acrylamide ratio $30: 0.2)$ and blotted onto nitrocellulose membranes (Bio-Rad). The antibodies employed for immunoblots are the following: rabbit anti-p53 polyclonal Ab (FL-393), rabbit anti-ERK2 polyclonal Ab (C-14), mouse anti-cyclin D1 moAb (72-13G), and mouse anti-MEK1 moAb (H8) (all from Santa Cruz); mouse anti-activated MAPKs (ERK1 and 2) moAb (clone MAPK-YT) (Sigma); mouse anti-human p21 moAb (6B6) (Pharmingen); rat anti-HA moAb (12CA5) (Roche); mouse anti-BrdU moAb (DAKO); mouse anti- $\alpha$-tubulin moAb (Sigma); mouse anti-MDM2 moAb (2A10) kindly provided by M Oren; HRP-conjugated goat anti-mouse, anti-rabbit, or anti-rat Abs (Cappel). Immunoreactivity was detected by the ECL chemoluminescence reaction kit (Amersham Corp.) following the manufacturer's instructions.

\section{Proliferation curves, BrdU and thymidine incorporation, and cell cycle analysis}

Approximately $1 \times 10^{5}$ cells were plated in replica $35 \mathrm{~mm}$ Petri dishes and infected with adenoviruses. Cell numbers and viability were determined by direct counting with trypan blue exclusion.

For the determination of DNA synthesis, cells were incubated in the presence of $20 \mu \mathrm{M} \mathrm{BrdU}$ (Sigma) for $2 \mathrm{~h}$, fixed in methanol/acetone $1: 1$ ( $v: v)$ and subjected to indirect immunofluorescence with a mouse anti$\mathrm{BrdU}$ moAb (DAKO) and FITC-conjugated anti-mouse serum (Cappel). Nuclei were counterstained with $1 \mu \mathrm{g} / \mathrm{ml}$ Hoechst 33258 dye. At least 500 cells per dish were counted. Alternatively, cells plated in quadruplicate in 24-well plates were incubated for $1 \mathrm{~h}$ with $\left[{ }^{3} \mathrm{H}\right]$ thymidine, lysed and c.p.m. measured at the $\beta$-counter. The DNA content was evaluated by cytofluorimetry with an Epics XL analyzer (Coulter Corporation). Analyses of GFP-positive and GFP-negative cells were performed as described. ${ }^{41}$

\section{In vitro kinase assay}

TCEs were prepared in lysis buffer $(0.2 \%$ Triton X-100, $50 \mathrm{mM}$ Tris- $\mathrm{HCl} \mathrm{pH}$ 7.5, $5 \mathrm{mM}$ EDTA, $1 \mathrm{mM}$ PMSF, $5 \mathrm{mM}$ sodium orthovanadate, $50 \mathrm{mM} \mathrm{NaF}$, $5 \mathrm{mM}$ EGTA, $5 \mu \mathrm{g} / \mathrm{ml}$ aprotinin, and $10 \mu \mathrm{g} / \mathrm{ml}$ leupeptin), sonicated, and clarified. Equal amounts of proteins (500 $\mu \mathrm{g} / \mathrm{sample})$ were immunoprecipitated with anti-ERK2 C-14 Ab or anti-HA $12 \mathrm{CA} 5$ moAb preadsorbed to protein $\mathrm{G}-$ Sepharose beads (KPL). Immune complexes were washed and incubated for $15 \mathrm{~min}$ at $30^{\circ} \mathrm{C}$ in kinase buffer $(20 \mathrm{mM}$ Hepes $\mathrm{pH} 7.4$, $10 \mathrm{mM} \mathrm{MgCl}_{2}, 1 \mathrm{mM}$ DTT, $200 \mu \mathrm{M}$ sodium orthovanadate) supplemented with $3 \mu \mathrm{Ci}$ of $\gamma=\left[{ }^{32} \mathrm{P}\right] \mathrm{ATP}, 50 \mu \mathrm{M}$ of cold $\gamma$-ATP, and $20 \mu \mathrm{g}$ of MBP (Sigma). The phosphorylated substrate was analyzed by $15 \%$ SDS-PAGE and autoradiography.

\section{Plasmids and transfections}

The following plasmids were employed: pEXV3-MAPKK ${ }^{\text {his }}$, encoding for a constitutively active mutant of MEK1 (S217E/S221E); ${ }^{3}$ pCMV-wtERK2$\mathrm{HA}$, obtained by cloning the HA-tagged murine wild-type erk2 cDNA (kindly provided by MJ Weber) into the pcDNA3.1 vector (Invitrogen); pGFP-C1, encoding for the green fluorescent protein; pCMV-D319N and pCMV-D335A, obtained by site-directed mutagenesis (Stratagene) of the pCMV-wtERK2-HA vector.

Transfections were performed with the BES-modified calcium phosphate method. The pBabe-puro vector ${ }^{42}$ carrying the puromycin resistance gene was cotransfected with the vectors of interest at a 1:10 molar ratio. Transfected cells were selected with $2 \mu \mathrm{g} / \mathrm{ml}$ of puromycin.

\section{Pulse chase and immunoprecipitation}

Cells were starved for $1 \mathrm{~h}$ in methionine-free medium (MEM Eagle, GIBCO-BRL), labeled for $90 \mathrm{~min}$ in the presence of $100 \mu \mathrm{Ci} / \mathrm{ml}$ of $\left[{ }^{35}\right.$ S]methionine (Dupont/NEN), and chased with $1.5 \mathrm{mg} / \mathrm{ml}$ of cold methionine. Cell lysis was performed at different time points. Equal amounts of total proteins were immunoprecipitated with C-14 Ab, resolved on SDS-PAGE, and processed for fluorography. Gel scan was performed on an Epson Perfection $1240 \mathrm{U}$ and analyzed by a Molecular Dynamics, Image Quant.

\section{In vitro cleavage assay}

Proteins were in vitro-translated and ${ }^{35}[S]$ methionine-labeled using the TNT Coupled Wheat Germ Extract Systems (Promega) and incubated for 60 or $90 \mathrm{~min}$ at $37^{\circ} \mathrm{C}$ in caspase buffer $(25 \mathrm{mM}$ Hepes, $1 \mathrm{mM}$ EDTA, $5 \mathrm{mM}$ DTT, $0.1 \%$ CHAPS, pH 7.5) with $2 \mu$ of recombinant caspase-3 (Upstate Biotechnology) or $100 \mu \mathrm{g}$ of TCEs from C2C12 cells. The reactions were analyzed by SDS-PAGE and fluorography.

\section{In vivo caspase detection and TUNEL assay}

Activation of caspases in live cells was measured by the CaspaTag ${ }^{\mathrm{TM}}$ Caspase-3 (DEVD) or fluorescein caspase (z-VAD) activity kit (Intergen Company) following the manufacturer's instructions. Fluorescence intensity of PI-negative cells was measured by cytofluorimetric analyses with an Epics XL analyzer (Coulter Corporation). Double immune-staining for active caspase-3 and apoptotic DNA fragmentation was performed with anti-cleaved-caspase-3 (Asp175) polyclonal Ab (Cell Signaling) and with a fluorescent In Situ Cell Death Detection kit (Roche) following the manufacturer's instructions.

\section{Acknowledgements}

This paper is dedicated to the memory of Franco Tatò, maestro of science and humanity. We thank him for all he gave us. We thank all the people cited in the text for their generous gifts of reagents. We are grateful to $F$ Moretti, A Zeuner, and R De Maria for helpful advice and discussion on the caspase work, to S Bacchetti for her comments on the manuscript, and to S lacovelli for technical support. This study was supported by Associazione Italiana per la Ricerca sul Cancro and Ministero della Salute. The authors declare that they have no competing financial interests.

\section{References}

1. Lewis TS, Shapiro PS and Ahn NG (1998) Signal transduction through MAP kinase cascades. Adv. Cancer Res. 74: 49-139

2. Marshall CJ (1995) Specificity of receptor tyrosine kinase signaling: transient versus sustained extracellular signal-regulated kinase activation. Cell 80 : 179-185

3. Cowley S, Paterson H, Kemp P and Marshall CJ (1994) Activation of MAP kinase kinase is necessary and sufficient for PC12 differentiation and for transformation of NIH 3T3 cells. Cell 77: 841-852

4. Lin AW, Barradas M, Stone JC, van Aelst L, Serrano M and Lowe SW (1998) Premature senescence involving p53 and p16 is activated in response to constitutive MEK/MAPK mitogenic signaling. Genes Dev. 12: 3008-3019

5. Ries S, Biederer C, Woods D, Shifman O, Shirasawa S, Sasazuki T, McMahon $M$, Oren M and McCormick F (2000) Opposing effects of Ras on p53: transcriptional activation of $\mathrm{mdm} 2$ and induction of $p 19^{\mathrm{ARF}}$. Cell 103: $321-330$ 
6. Serrano M, Lin AW, McCurrach ME, Beach D and Lowe SW (1997) Oncogenic ras provokes premature cell senescence associated with accumulation of p53 and p16INK4a. Cell 88: 593-602

7. Lowe SW (1999) Activation of p53 by oncogenes. Endocr. Relat. Cancer 6 : $45-48$

8. Lee SW, Fang L, Igarashi M, Ouchi T, Lu KP and Aaronson SA (2000) Sustained activation of Ras/Raf/mitogen-activated protein kinase cascade by the tumor suppressor p53. Proc. Natl. Acad. Sci. USA 97: 8302-8305

9. Deguin-Chambon V, Vacher M, Jullien M, May E and Bourdon J-C (2000) Direct transactivation of c-Ha-ras gene by p53: evidence for its involvement in p53 transactivation activity and p53-mediated apoptosis. Oncogene 19: 5831-5841

10. Peeper DS, Upton TM, Ladha MH, Neuman E, Zalvide J, Bernards R, DeCaprio JA and Ewen ME (1997) Ras signalling linked to the cell-cycle machinery by the retinoblastoma protein. Nature 386: $177-181$

11. Bates S, Phillis AC, Clark PA, Stott F, Peters G, Ludwig RL and Vousden KH (1998) p14 ARF links the tumour suppressors RB and p53. Nature 395: 124-125

12. Sherr CJ and Weber JD (2000) The ARF/p53 pathway. Curr. Opin. Genet. Dev. 10: 94-99

13. Pearson M, Carbone R, Sebastiani C, Cioce M, Fagioli M, Saito S, Higashimoto Y, Appella E, Minucci S, Pandolfi PP and Pelicci PG (2000) PML regulates p53 acetylation and premature senescence induced by oncogenic Ras. Nature 406 : 207-210

14. Wang X, Martindale JL and Holbrook NJ (2000) Requirement for ERK activation in cisplatin-induced apoptosis. J. Biol. Chem. 275: 39435-39443

15. Manni I, Mazzaro G, Gurtner A, Mantovani R, Haugwitz U, Krause K, Engeland K, Sacchi A, Soddu S and Piaggio G (2001) NF-Y mediates the transcriptional inhibition of the cyclin B1, cyclin B2, and cdc25C promoters upon induced G2 arrest. J. Biol. Chem. 276: 5570-5576

16. Fukuda M, Asano S, Nakamura T, Adachi M, Yoshida M, Yanagida M and Nishida E (1997) CRM1 is responsible for intracellular transport mediated by the nuclear export signal. Nature 390: 308-311

17. Freedman DA and Levine AJ (1998) Nuclear export is required for degradation of endogenous p53 by MDM2 and human papillomavirus E6. Mol. Cell. Biol. 18: 7288-7293

18. Smart P, Lane EB, Lane DP, Midgley C, Vojtesek B and Laín S (1999) Effects on normal fibroblasts and neuroblastoma cells of the activation of the p53 response by the nuclear export inhibitor leptomycin B. Oncogene 18: 7378-7386

19. Innocente SA, Abrahamson JL, Cogswell JP and Lee JM (1999) p53 regulates a G2 checkpoint through cyclin B1. Proc. Natl. Acad. Sci. USA 96: 2147-2152

20. El-Deiry WS, Tokino T, Velculescu VE, Levy DB, Parsons R, Trent JM, Lin D, Mercer WE, Kinzler KW and Vogelstein B (1993) WAF1, a potential mediator of p53 tumor suppression. Cell 75: 817-825

21. Gottlieb E and Oren M (1998) p53 facilitates pRb cleavage in IL-3-deprived cells: novel pro-apoptotic activity of p53. EMBO J. 17: 3587-3596

22. Bachelder RE, Ribick MJ, Marchetti A, Falcioni R, Soddu S, Davis KR and Mercurio AM (1999) p53 inhibits $\alpha 6 \beta 4$ integrin signaling by promoting the caspase 3-dependent cleavage of AKT/PKB. J. Cell Biol. 147: 1063-1072

23. De Maria R, Zeuner A, Eramo A, Domenichelli C, Bonc, D, Grignani $F$, Srinivasula SM, Alnemri ES, Testa U and Peschle C (1999) Negative regulation of erythropoiesis by caspase-mediated cleavage of GATA-1. Nature 401 489-493

24. Cohen GM (1997) Caspases: the executioners of apoptosis. Biochem. J. 326 $1-16$
25. Brummelkamp TR, Bernards R and Agami R (2002) A system for stable expression of short interfering RNAs in mammalian cells. Science 296: $550-553$

26. Ko LJ and Prives C (1996) p53: puzzle and paradigm. Genes Dev. 10: 1054-1072

27. Vousden KH (2000) p53: death star. Cell 103: 691-694

28. Dasika GK, Lin SC, Zhao S, Sung P, Tomkinson A and Lee EY (1999) DNAdamage-induced cell cycle checkpoints and DNA strand break repair in development and tumorigenesis. Oncogene 18: 7883-7899

29. Wrigth JH, Munar E, Jameson DR, Andreassen PR, Margolis RL, Seger R and Krebs EG (1999) Mitogen-activated protein kinase activity is required for the G2/M transition of the cell cycle in mammalian fibroblasts. Proc. Natl. Acad. Sci. USA 96: $11335-11340$

30. Hitomi M and Stacey DW (2001) Ras-dependent cell cycle commitment during G2 phase. FEBS Lett. 490: 123-131

31. D'Orazi G, Soddu S and Sacchi A (2000) Activation of p53/p21 waf1 pathway is associated with senescence during v-Ha-ras transformation of immortal $\mathrm{C} 2 \mathrm{C} 12$ myoblasts. Anticancer Res. 20: 3497-3502

32. Widmann C, Gibson S and Johnson GL (1998) Caspase-dependent cleavage of signaling proteins during apoptosis. J. Biol. Chem. 273: 7141-7147

33. Pochampally R, Fodera B, Chen L, Shao W, Levine EA and Chen J (1998) A $60 \mathrm{kD}$ MDM2 isoform is produced by caspase cleavage in non-apoptotic tumor cells. Oncogene 17: 2629-2636

34. Gentiletti F, Mancini F, D'Angelo M, Sacchi A, Pontecorvi A, Jochemsen AG and Moretti $F(2002)$ MDMX stability is regulated by $p 53$-induced caspase cleavage in NIH-3T3 mouse fibroblasts. Oncogene 21: 867-877

35. Fang L, Li G, Liu G, Lee SW and Aaronson SA (2001) p53 induction of heparinbinding EGF-like growth factor counteracts p53 growth suppression through activation of MAPK and PI3K/Akt signaling cascades. EMBO J. 20: 1931-1939

36. Sabbatini P and McCormick F (1999) Phosphoinositide 3-OH kinase (PI3K) and PKB/Akt delay the onset of p53-mediated, transcriptionally dependent apoptosis. J. Biol. Chem. 274: 24263-24269

37. Kinzler KW and Vogelstein B (1996) Lessons from hereditary colorectal cancer. Cell 87: $159-170$

38. D'Orazi G, Marchetti A, Crescenzi M, Coen S, Sacchi A and Soddu S (2000) Exogenous wt-p53 protein is active in transformed cells but not in their nontransformed counterparts: implications for cancer gene therapy without tumor targeting. J. Gene Med. 2: 11-21

39. Del Bufalo D, Cucco C, Leonetti C, Citro G, Dagnano I, Benassi M, Geiser T, Zon G, Calabretta B and Zupi G (1996) Effect of cisplatin and c-myb antisense phosphorothioate oligodeoxynucleotides combination on a human colon carcinoma cell line in vitro and in vivo. Br. J. Cancer 74: 387-393

40. Graham F and Prevec L (1991) Manipulation of adenovirus. In Methods of Molecular Biology, Murray EJ, ed (Clifton, NJ: Humana Press) Vol. 7, pp. $109-128$

41. Agami R, Blandino G, Oren M and Shaul $Y$ (1999) Interaction of c-Abl and p73alpha and their collaboration to induce apoptosis. Nature 399: 809-813

42. Morgenstern JP and Land $H$ (1990) Advanced mammalian gene transfer: high titre retroviral vectors with multiple drug selection markers and a complementary helper-free packaging cell line. Nucleic Acids Res. 18: 3587-3596

43. Shaulian E, Zauberman A, Ginsberg D and Oren M (1992) Identification of a minimal transforming domain of $p 53$ : negative dominance through abrogation of sequence-specific DNA binding. Mol. Cell. Biol. 12: 5581-5592

Supplementary Information accompanies the paper on Cell Death and Differentiation website (http://www.nature.com/cdd). 